This is a self-archived version of an original article. This version may differ from the original in pagination and typographic details.

Author(s): Eteläpelto, Anneli

Title: Emerging conceptualisations on professional agency and learning

Year: 2017

Version:

Copyright: @ Springer International Publishing AG 2017

Rights: In Copyright

Rights url: http://rightsstatements.org/page//nC/1.0/?language=en

Please cite the original version:

Eteläpelto, A. (2017). Emerging conceptualisations on professional agency and learning. In M. Goller, \& S. Paloniemi (Eds.), Agency at Work : An Agentic Perspective on Professional Learning and Development (pp. 183-201). Springer Netherlands. Professional and Practice-based Learning, 20. https://doi.org/10.1007/978-3-319-60943-0_10 


\title{
Emerging conceptualisations on professional agency and learning
}

Anneli Eteläpelto

Department of Education, University of Jyväskylä, Finland

Anneli Eteläpelto, Corresponding author

University of Jyväskylä, Department of Education

P.O. Box 35 (RUU D437)

40014 University of Jyväskylä, Finland

Tel: +358405755490

E-mail: anneli.etelapelto@jyu.fi

\author{
A list of the terms that could be listed in the index: \\ Professional agency \\ Work-related learning \\ Socio-cultural \\ Individual subject \\ Professional identity \\ Subject-centred socio-cultural approach \\ Emotions \\ Subject-centred sociocultural approach \\ Conceptualisation of agency
}




\section{Emerging conceptualisations on professional agency and learning}

This chapter provides an evaluative summary of the major contributions from the first section of this book, comprising conceptualisations on professional agency and work-related learning. The evaluation focuses on the differences, similarities, and strengths of the approaches and conceptualisations touched on. The focus is, first of all, on how the core meanings of agency and the agentic perspective are understood. Secondly, the approaches are addressed according to their view of how the contextual aspects of working life relate to agency. Thirdly, attention is given to the practical conclusions deriving from different understandings of agency. The present chapter thus elaborates how these understandings relate to work-related learning, and to the development of work practices. It further discusses the implications of the different conceptualisations of agency for future research, and for the development of agentic practices at work, with attention given also to life-long career construction. On the basis of the summary, the chapter seeks to identify the most important gaps in current knowledge. These will require research on agency in work-related learning, and on individual lifelong career construction.

Keywords: Professional agency; work-related learning; socio-cultural context; individual subject; professional identity, emotions, conceptualisation

\section{Introduction}

\subsection{Variations in ways of understanding agency}

The first section of this edited collection has presented widely differing conceptualisations of professional agency. In a variety of ways, the chapters contribute to discussions on professional 
agency, and on agentic perspectives concerning professional learning. In doing so, they provide novel accounts of work-related learning and development. In addition, the chapters offer analytical lenses, usable in future research. The conceptualisations presented also provide theoretical frameworks and analytical tools that can be applied in supporting the career constructions of individuals, amid the changing demands of working life.

An understanding of agentic perspectives is always imbued by societal contexts, comprising economic, material, and cultural circumstances. The reader will note the wide variation in local circumstances, and in the situations of the work organisations in the studies reported. The authors in the first eight chapters come from Australia, Germany, Finland, the UK, and the USA. Although these all represent developed Western countries with many similarities in their socio-cultural and working life conditions, there are also significant differences in their leadership practices, their interaction cultures, and the discourses used to characterise ideal practices for developing working life. In addition, linguistic challenges emerge relating to the local policy discourses used in promoting work-related learning, and the development of working life. For example, in German, it is difficult to find a word with a similar meaning to the English word agency. Instead - as the chapters of our German authors demonstrate - efforts to develop production and to promote work-related learning are conceptualised in terms of innovative work behaviour and intrapreneurship (see section 2.3). In fact, the phenomena presented mirror fairly closely what is understood by "agency", and by agentic perspectives on work-related learning and development. Nevertheless, one can see here how differences in cultural discourses have the potential to influence how we understand agentic perspectives at work.

Despite exhibiting a range of conceptualisations and theoretical lenses, the approaches have more similarities than differences. The similarities concern an understanding of agency as a phenomenon implying active human participation. This encompasses 
influencing, transforming, developing, and initiating new ideas, or taking a critical stance towards existing practices at work. However, agency can also be seen as involving primarily capacities and potentials, and the power to engage in the various activities mentioned above.

Rather than implying a need to find a single way of understanding agency, the differing conceptualisations can be seen as a richness. They provide a good foundation for a deeper understanding of the phenomenon. In fact, the perspectives of the authors can be seen as complementary rather than conflicting, with possibilities to enrich theoretical discussions. This emerges in the manner in which the surrounding context seems to lead to different understandings of the role of agency in work-related learning. The studies reported indicate how different kinds of social, material, and economic circumstances can resource and/or constrain agency within different societal and working life conditions. The resources and constraints can involve, for example, different kinds of employment relations (permanent or full-time work vs. contract-based project work), differences in the role of technology and in the tools for working, forms of work practices, leadership styles, and other organisational circumstances.

In addition, the previous chapters demonstrate the range of occupational domains within which conceptions of agency have been developed. Professional work provides the setting for vocational and adult education teachers, nurses, wholesale employees, and freelancers in the film and media industry. Such a spectrum of domains and employment relations facilitates nuanced views when one is seeking to further analyse agency and agentic perspectives on work-related learning.

This chapter seeks to provide an evaluative summary of the major contributions from the first section of this book. The first section (i.e. the first eight chapters of this book) conceptualises agency via different theoretical approaches. Hence, a comparison of the agentic 
perspectives needs to focus on the differences and similarities, and also on the different strengths of the approaches and conceptualisations touched on. Here it may be helpful to scrutinise the chapters from four different angles.

\subsection{An overview of the perspectives applied in the previous chapters}

First of all, one can focus on how the core meanings of agency and the agentic perspective are understood. The main differences lie in whether agency is seen as a behavioural process, or else as a more permanent individual or collective characteristic, leading to certain kinds of behaviour. In addition, within each of these options, differences can be identified. Thus, there are differences in what are seen as core aspects of individual behaviour (involving notably situational cognitive, motivational, and affective processes), and differences also in relation to long-term career-construction processes. In parallel with these, on the level of individual/collective traits, differences emerge in the extent to which relational, collective, and social aspects of agency are deemed to be salient.

Secondly, approaches differ in how they consider the contextual aspects of working life to relate to agency. Here, there are two extremes, comprising on the one hand, a view of the societal levels and historical configurations of working lives as fundamental determinants of agency, and on the other hand, a view of people as separate individuals, each with an individually constructed capacity and situationally emerging potential to practise agency. These different perspectives have different practical consequences concerning how agentic perspectives could contribute to work-related learning and development. If agency is understood as an (individual) permanent and stable characteristic, one might pay less attention to developing working life conditions, preferring rather to develop more refined assessment tools and measurement instruments. These would make it possible to select employees with the degree of agency required in a given type of employment. One can argue that such an exclusive application of agency would neglect the need to enhance work practices, and would be harmful 
in the long run. By contrast, a more elaborated understanding of agency - as something practised within and through specific working-life conditions, and including affordances for as well as obstacles to the promotion of agency - can be seen as more fruitful for developing working life, and for encouraging the innovations demanded in a competitive global economy.

Thirdly, the present chapter addresses the practical conclusions implied by different understandings of agency. This includes asking how the different understandings relate to work-related learning, and the development of work practices. In this connection we need to discuss the conceptions of work-related learning that may be involved in the different understandings of agency, and overall, how agency is seen as related to learning. In some cases, the practice of agency is seen as mediating or enabling work-related learning. In other cases it is viewed as almost identical to learning. In all cases, we are dealing with an agentic perspective on work-related learning. This would imply that our conception of learning at work has evolved in such a manner as to view all meaningful learning in the work context as agentic ${ }^{1}$. It is true that a view of agentic practice as identical to work-related learning would be problematic in terms of making an analytical distinction between the two concepts. However, it seems reasonable to assume that there is at least an overlap between the concepts of agency and workrelated learning, notably as regards the transformative aspects of agency. This is particularly the case if we adopt an activity/practice-based understanding of professional learning.

Fourthly, this chapter discusses what the different conceptualisations of agency imply for future research, and for development towards agentic work practices. This is important, since one can assume that different conceptualisations of agency will provide

1 The idea of agentic learning has recently moved to the school level, with learners being seen as active agents. Since 2016, following reforms of the national curriculums in Finland, learning at all levels of schooling (from pre-school to adult education) has been defined as agentic learning. 
different kinds of analytical lenses for empirical research, touching on the operationalisation, measurement, and development of agency at work, and the promotion of life-long career construction. On the basis of the author's evaluative summary, this chapter will also seek to identify the most important gaps in our knowledge, requiring research on agency in work-

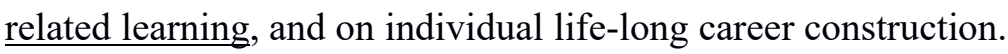

In this chapter, the author's own understanding and analytical lenses could well influence the evaluation. It thus seems fair to make these lenses explicit. For this purpose, the Subject-Centred Socio-Cultural (SCSC) approach to professional agency is briefly described below.

\subsection{The Subject-Centred Socio-Cultural (SCSC) perspective as a lens on agency}

The SCSC perspective has made use of social science and post-structural notions of agency. It encompasses subject-centred socio-cultural notions of work-related learning, and includes also life-course and identity approaches to agency (Eteläpelto, Vähäsantanen, Hökkä and Paloniemi, 2013). On the basis of these notions, agency is understood as a practice-based process of action and behaviour which individuals or collectives enact through influencing, making choices, and

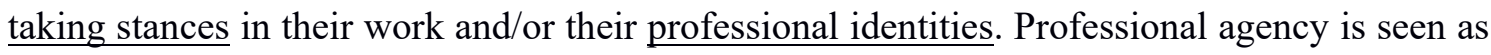
enacted in and through the material and socio-cultural conditions of work. Professional identity, for its part, refers to the subject's professional sense of the self, as a personal and social entity. Professional identity thus encompasses the subject's personal interests, goals, and ethical

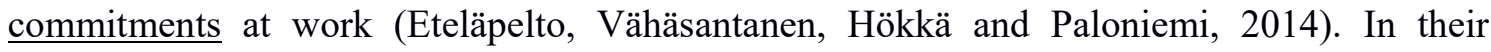
empirical research on agency at work (which takes the SCSC approach as a starting point), the researchers have conducted several qualitative studies on agency, concerning how it is enacted, resourced, and constrained, for example in the fields of education, health care, and the IT industry (Eteläpelto et al., 2015; Hökkä, Vähäsantanen and Mahlakaarto, 2017; Vähäsantanen et al., 2016). The understanding of agency within the approach applied has been further 
enriched by intervention studies, which have operated at individual, collective, and organisation levels in a complementary manner (Vähäsantanen et al., 2016; Collin, Paloniemi and Vähäsantanen, 2015).

One recent endeavour within the SCSC approach has been aimed at developing a quantitative instrument for measuring agency in work organisations. Based on a comprehensive survey on agency in different work contexts, the research group has conducted statistical validation of a multidimensional model comprising three major components of professional agency. These have been identified as (a) influencing at work, (b) contributing to work practices, and (c) the negotiation of professional identity (Vähäsantanen et al., 2016). These components have enriched the current understanding of professional agency within the approach adopted, which takes as a starting point the affordances and constraints operating in the work context, including official and unofficial facets of power. The aim has been to understand the role of agency in promoting individual employees' long-term career construction, including their possibilities for negotiating their professional identities. Overall, this endeavour seeks to contribute to sustainable learning and wellbeing at work.

In accordance with policy-level discussion (in Finland), it can be anticipated that the usefulness of the agency perspective will derive from its double function. Thus, agency can contribute (a) to development and innovativeness in creating goods and services, and (b) to the wellbeing, career construction, and continuous learning of employees. In the following paragraphs this is taken as a basis for discussing the various theoretical perspectives presented in the previous chapters. Roughly speaking (as analysed via the SCSC approach) the chapters in question conceptualise active agency from three major perspectives. These encompass (a) influencing and participating in one's work, within and through social, material, and power-related conditions; (a) transformative, developmental, and innovative work behaviour; (b) the 
negotiation of professional identity, viewed as encompassing values, interests, goals, competences, and career construction over the long term (Vähäsantanen et al., 2016).

This diagram outlines the components of professional agency as understood in the SCSC approach.

- Insert Figure 1 about here -

Below, I will evaluate how different conceptualisations depict (a) the core processes of agency, (b) socio-cultural conditions, and (c) professional subjects.

\section{Core interpretations of agency}

\subsection{Agency understood as transformative behaviour}

In viewing agency as a behavioural or activity process, agency is not understood purely as a matter of maintaining and reproducing behaviour. Rather, it is active behaviour, with transformative influences. Thus, agency is a matter of making changes to a previous or present state of affairs. The transformative emphasis is to some degree present in the understandings of agency presented in all the previous chapters (by Evans, Goller and Harteis; Hökkä et al.; Hopwood; Kwon; Messmann and Mulder; Smith; Wiethe-Korprich et al.; all in this volume). If agency is seen from a subjective life-course perspective (Evans; Hökkä et al.; Kwon; Smith), active influence is directed at the person's life and future life-course. This may include decisions concerning the individual's current work situation during the renegotiation of professional identity. However, these active processes of enacting life-course agency have a long-term influence on the direction of one's life, even beyond one's career and work situation. In the case of Kwon, this is manifested in the subject's active and sustainable (but challenging) formation of a career continuum and its future-oriented perspective. In the chapter by Hökkä et 
al., transformative agentic actions within a life-course are manifested when employees resign from their work to become independent entrepreneurs, or when vocational teachers renegotiate their professional identities as a consequence of a curriculum reform. Generally speaking from a life-course perspective - transformative agency tends to manifest itself as making active choices and decisions concerning one's individual career construction. In previous literature, such agency has been termed life-course agency (e.g. Hiltin and Elder, 2007).

A similar future orientation is present in understandings of agentic behaviour as transformative in terms of developing something new within work practices, products, tools, and conditions at work. In these understandings, agency is seen as a transformative and generative process of innovative work behaviour (Messmann and Mulder, this volume), or as intrapreneur behaviour (see section 2.3) involving the generation, planning, and implementation of innovative projects within organisational practices (Wiethe-Korprich et al., this volume). Agentic processes are thus seen as the proactive construction of plans, or as the recognition of opportunities for new initiatives, plus their implementation (Goller and Harteis, this volume). Here, one can recognise a transformative influence on work practices or products. Active behaviour may include, for example, recognising and suggesting innovations aimed at new and competitive products, and at reforming processes within the work.

Looked at in detail, agentic actions can be viewed as cognitive and rational. However, they can also include including motivational and volitional facets, such as the application of "grit", introduced by Kwon. In the chapters of Wiethe-Korprich et al. and of Messmann and Mulder, agentic actions are understood primarily as creative and generative processes, leading to innovation in development. By contrast, emotional processes have received relatively little attention in connection with agentic processes. Although Evans briefly refers to feelings in connection with individual behaviour (in referring to thinking, feeling, and acting), the chapter by Hökkä et al. is the only one which thoroughly moves the discussion in 
this direction. Thus, it discusses the crucial role of emotions, and how they are related to employees' and leaders' decision-making concerning their agency at work and their career construction. In addition, emotions are addressed by Hökkä et al. in relation to the pressure on employees and leaders (at middle and upper level) to renegotiate their professional identities. It can be expected that in the future, there will be a stronger focus on the emotional aspects in agentic processes, and in the enactment of professional agency,

\subsection{Agency as relational action}

Work behaviour and work-related learning are usually seen as social processes. Traditionally they take place in work organisations, but increasingly also in private and, for example, virtual contexts. It is understandable that the social nature of work behaviour is to some extent present (and is at least not denied) in the conceptualisations of agency presented in this book. However, in some of the definitions, the practice of agency is seen primarily (i.e. at its core) as a relational phenomenon.

Referring to Edwards's (2005) concept of relational agency, Hopwood does not view agency as a personal property or characteristic. Rather he sees it as arising through the dialectic between person and practice (and also as connected to the capacity to influence conditions that affect development). Agency is seen by Hopwood as required especially in nonroutine situations, referred to as "epistemic dilemmas". Such dilemmas demand fresh knowledge, and they also produce new knowledge. In such an understanding, agency is seen as identical with the learning that occurs in work practices, when a person solves problems arising from work tasks. The practice of agency is examined by Hopwood via a cultural-historical approach; this reflects Vygotskian (Vygotskij, van der Veer, \& Valsiner, 1994) roots and Leontief's (1978) work on motives (Hopwood, this volume), but does not follow the systemic approach associated with cultural-historical activity theory (CHAT), as presented by Engeström 
and others. Hopwood follows Edwards's notion of relational agency and Knorr Cetina's (2001) notion of epistemic objects. Agency is seen both as an activity and as learning, but as involving also an individual capacity for recognising and solving epistemic dilemmas. These are characterised by partial and incomplete knowledge, by the fragility of what is known, and by the unstable nature of the knowledge in question. Agency is analysed in terms of professionals' capacity to recognise and respond to such dilemmas, in the context of family services. This kind of knowledge work is seen as relational and emergent, and thus as demanding agentic capacity and practice from professionals. Although Hopwood partly sees agency as a capacity, he concludes with the opinion that agency is not a matter of individual possession; rather, the exercise of agency is something arising from the dialectics between the person and the practice, the individual and the collective, the professional and the client.

This is close to Smith's understanding of the relationships between agency and work-related learning. In discussing personal agency, Smith is concerned with the set of influences that can be attributed to individuals when they contribute to socio-cultural activities and practices. His somewhat complex definition of agency implies that agency is intertwined with and partly identical with the processes of learning in, through, and for work. Workers are seen as active learners who are engaged in learning through the practices that constitute the work, and for Smith, learning activities can be conceptualised as epistemological agency. This view is based on three aspects of agency: (a) agency as a property, (b) agency as a relationship, and (c) agency as transformation. Smith sees agency as a mediating concept in the worklearning relationship, and he emphasises the socio-personal practice of work-related learning. To illustrate such personal agency at work he gives an account of an emotionally charged situation in which a boss shouts aggressively at a new employee. The employee is seen as practising agency by taking a passive stance, accompanied by apparent embarrassment. Such a passive stance, although here viewed as highly agentic as a means of coping with the situation, 
would not always be understood as typical agentic behaviour. However, Smith argues that from the perspective of the employee, such behaviour leads to meaningful maintenance in terms of the outcome. This demonstrates how agency is manifested as a social practice; the purpose of agentic actions is negotiated in the social interaction and in the broader context. It is these that make agentic practices meaningful and consequential.

The view of agency as transformational in relation to a previous state is similar to other understandings of agency. However, differences exist regarding the object of transformation. Agency can be conceptualised as relationship-in-action. Based on Billett's (2008) suggestion concerning the relational interdependence between personal agency and the social affordances of the workplace, Smith sees learning as personal development, and as altered practices emerging from the relationship between the individual and the social domain. In the work context, this is manifested for example as friendliness between co-workers friendliness which is open and which both gives and accepts support in emotionally challenging situations. Work-related learning is conceptualised by Smith as epistemological agency, which is defined as the individual's purposeful generation of the occupational knowledge, skills, and practices comprising work. Agency is to be considered developmentally, exerted across a life of engagement in social practice.

\subsection{Agency as an innovative and creative process}

Modern business life calls for innovative thinking. Hence, agency in working life is increasingly understood as requiring an entrepreneurial orientation and entrepreneurial skills, including also competence in intrapreneurship. This is addressed in the present book by Wiethe-Korprich et al. In their view, an important 21 st century skill can be identified in employees' own entrepreneurial ways of thinking and acting within an organisation. On the basis of a literature review, the authors developed a model encompassing the components of intrapreneurship (IP) 
behaviour, which are said to comprise, primarily, identifying and implementing opportunities for innovation. The authors start with Pinchot's (1985) definition of IP, as something that originates from an individual who acts like an entrepreneur while having the role of an employee. Nevertheless, they consider it more fruitful to view IP as a process, rather than as an individual disposition. Hence, it constitutes one of the processes by which new ventures, products, services technologies, administrative techniques, strategies, and competitive projects are developed and implemented within organisations.

The authors make it clear that IP is not a stable characteristic, but rather a malleable facet of human behaviour, and that it can change in response to educational interventions. Such malleability is seen as bound up with cognitive, motivational, ethical, volitional, and social aspects of behaviour. Having conducted a literature search, the authors identified 78 relevant articles. From an analysis of the IP-related dispositions exhibited, they

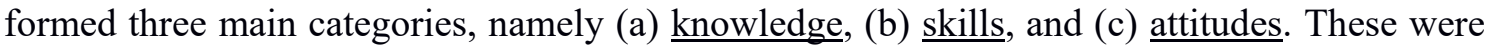
seen as comprising social competences (such as assertiveness), team and leadership competences, resilience, emotional intelligence, proactiveness, goal-achieving behaviour, and autonomous activity. The model developed so far appears to have considerable potential in covering the kinds of knowledge and skills related to the development and implementation of new ideas. The authors have arrived at a comprehensive, fine-grained, and action-based IP competence model. The constructs identified overlap in most respects with what is termed more generally work agency (see also Goller and Harteis, this volume).

Messmann and Mulder (this volume) similarly conceptualise work agency as innovative behaviour, and see innovation development as an employee-driven process. Messmann and Mulder identify four dimensions of innovative work behaviour; these are (a) opportunity exploration, (b) idea generation, (c) idea promotion, and (d) idea realisation. They emphasise that this is not to be viewed as a sequence, and that the dimensions are 
interdependent. They further elaborate the process of reflection, which they see as a necessary prerequisite for innovative behaviour in the workplace.

\section{How the individual subject is understood}

\subsection{Individuals in relation to agency}

The conceptualisations of agency in this book exhibit significant differences in how they thematise (or do not thematise) individual subjects. Differences concerning the nature and role of individual subjects seem further to emerge from the varying ontological understandings of agency. These relate to whether agency is seen as a behavioural process, or as an individual capacity to act, or as a set of individual characteristics (see also Harteis and Goller, 2014). Note than none of the conceptualisations in this book view agency purely as a set of stable characteristics belonging to an individual. Rather, agency is seen as (a) a capacity, and/or (b) a behavioural process, influenced by the social context of the work.

Goller and Harteis (this volume), who address agency from an individual employee perspective, propose as distinct components of agency (a) agency competence, (b) agency beliefs, and (c) agency personality. In modelling agency, they utilise literature on sociocognitive psychology, life-course research, and organisational behaviour. They see as crucial $\underline{\text { self-efficacy beliefs, }}$, and especially individual dispositions, by which people aim to take control over themselves and their environments; these are viewed as comprising individual agentic capacity. They consider three aspects of human agency, namely competences, beliefs, and personality, as having predictive value in the practice of agency. Goller and Harteis suggest that individual beliefs and competences relating to agency can be enhanced through appropriate training. By contrast, they understand agency personality as something more stable. In their theoretical starting points they refer to individual developmental affordances which can influence the development of an agentic personality. However, further discussion will be needed regarding individual ontogeny factors (such as dispositions of temperament and their 
malleability) before it may be possible to generalise from preliminary findings on the role of stable personality traits, or to consider their importance for agentic behaviour in the varying socio-cultural conditions of working life.

For Goller and Harteis (this volume), the actual practice of agency consists in

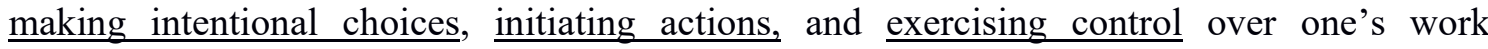
environment, and/or individual life. Goller and Harteis thus arrive at a compromise, understanding agency as existing both in individuals' capacities and in their actual behaviour. They see individual capacities as fairly stable, but as nevertheless influenced by workplace circumstances. In their empirical modelling of individual agentic behaviour, Goller and Harteis aim to explain both formal and informal workplace learning activities. However, in their view, future research will be needed to show how these individual components of agency interact with the work domain, and with contextual constraints, such as the power relations emerging from different leadership practices. So far, Goller and Harteis have utilised empirical data from geriatric nursing in creating their model.

In conceptualising agency at the individual level, differences further emerge in whether the individual is viewed in terms of a recent or current situation, or from a life-long perspective. Other differences emerge also, ranging from a focus on ability and competence (Goller and Harteis, this volume) to a focus primarily on professional identity (Hökkä et al., this volume). The latter notion includes ethical commitments, $\underline{\text { interests }}$, and ideals at work. It is possible to view the crafting and negotiation of professional identities (in terms of these commitments, interests, and ideals) as comprising, per se, the enactment of agency. Seen in this light, the primary object of agency enactment is not simply the work practice, but the subject's work identity. 
In defining agency, the previous chapters do not focus on the individual purely from a chronologically narrow perspective. In fact, more attention is given to individuals from a life-long (and life-wide) point of view. Such a perspective on agency is present within developmental socio-cultural approaches (e.g. Billett, 2008; Hitlin and Elder, 2006), and in certain life-course approaches (Evans, this volume; see also Eteläpelto et al., 2013). The studies in question present evidence concerning the role of life-course agency, and its manifestation in critical decisions. These can involve, for example, career decisions and the construction of work identities within different societal circumstances (Biesta and Tedder, 2015). However, Evans warns against viewing individual adults as self-contained, volitional beings engaged in individual projects. Instead, in accordance with her concept of bounded agency, individuals should be viewed in a manner that brings into focus the social, cultural, and relational dynamics of the person who is acting.

It is clearly important to determine how social circumstances influence individual employees' practice of agency, and how they practise agency through the circumstances in which they are placed. So far, we know that degrees of autonomy, and the possibilities to exert influence at work, are closely related to the nature of the agency practised in the work. For example, in Finland, where teachers have had considerable autonomy in their work, this has provided them with wide opportunities to practise professional agency. This implies that teachers' individual orientations, interests, goals, and pedagogical commitments - comprising their professional identities - can have a huge influence on how they organise their work at the classroom level (Eteläpelto, Hökkä and Vähäsantanen, 2015; Pappa, Moate, Ruohotie-Lyhty and Eteläpelto, 2017). Opportunities to influence and implement independent decisions - hence to practise agency - give more space for individual subjects to operate, as compared to a highlyregulated work environment. Importantly, since one's individual work identity has a huge influence on one's work, it also influences work-related learning. 
In the light of the considerations above, it appears important not to neglect individual subjects, including their work identities, when we address how agency is practised at work. Indeed, there is evidence of close reciprocal relationships between professional identity and the practice of agency (Buchanan, 2015). This is in fact why we assume, within our SCSC approach, that the practice of professional agency is closely intertwined with professional subjects' work-related identities, which are seen as consisting in their professional and ethical commitments, ideals, motivations, interests, and goals. Furthermore, we see it as highly likely that professional subjects' unique work experiences, knowledge, and competences function as individual developmental affordances for the practice of professional agency. These are especially influential in the practice of what we refer to as identity agency, or when agency is understood as career construction.

\subsection{Agency as individual career construction and identity negotiation}

Starting from a sociological framework, Kwon (this volume) suggests that we should widen previous notions of agency towards a more elaborated understanding of how agency is practised. This applies particularly to the construction of an educational and/or work career in a foreign context (see also section 2.1). Kwon refers to sociological discussion concerning the dialectics between social conditions and individual freedom. These are bound up with the notion that individuals do not have complete freedom, and that a balance needs to be found between normative patterns of society and individual volition. Kwon criticises previous discussions of agency, insofar as these have been limited to viewing agency purely in terms of individuals' subjective beliefs (involving a sense of control coupled with certain future-oriented expectations). This would seem to refer to the socio-cognitive concept of self-efficacy, which is strongly present in the psychology tradition. As an alternative, Kwon proposes the psychosociological concept of grit, which represents behavioural or action-oriented aspects of agency. 
Kwon's proposal involves a movement away from cognition towards action, and towards the exercise of power.

Kwon (this volume) refers to studies showing how beliefs in better life outcomes (for example in terms of career expectations) are associated with socioeconomic determinants, such as age, gender, race, education, and income. Studies have indicated that people with a higher sense of agency (understood as a subjective sense of control and achievement), are more likely to achieve better educational and occupational attainments. Kwon notes that in a sociological discussion of agency, Emirbayer and Mische (1998) suggested bringing temporality back into the concept of agency. Kwon emphasises the importance of temporality in terms of a person's orientation to the future. She notes that optimistic life expectations among adolescents are indeed strongly predictive of later life outcomes. However, as she suggests, the link between beliefs and actions is lacking; thus the concept of grit is proposed, as a factor which bridges the gap. Grit is understood as a disposition to pursue one's interests over the course of years. According to Kwon, it is a recently-developed concept predicting outstanding achievement. Grit is seen as a non-cognitive skill involving passion and perseverance, aimed at a long-term goal. Considered in more detail, grit is composed of two components, namely consistency of interest, and perseverance of effort (Duckworth et al., 2007). Kwon suggests adding grit as a behavioural component of agency. Grit in this sense would encompass behavioural tendencies manifested as working hard and persistently, in line with one's futuredirected orientation. However, as Kwon notes, future research will be needed on the background of grit, and how it can emerge.

Writing within a sociological framework, Evans (this volume) suggests a rethink of the role of personal agency and its limits. For her, agency is a bounded, life-long process that is both biographically produced and socially embedded. The concept of bounded agency emerged from comparative studies of young adults' education and work in England and 
Germany. The comparison showed how, within the highly structured Eastern German system, external factors were held to be responsible for failures in education and work. By contrast, English labour structures are part and parcel of a system that is difficult to read. It incorporates the belief that "opportunities are open to all". Hence, people tend to blame themselves for their failures in education and in the labour market.

Evans (this volume) suggests that individual biographical dispositions act in a close interaction with structural conditions. Agency is seen by Evans as socially situated, but not as determined by the environment. In line with this, people's own work identities influence how they respond, individually and collectively, to the structures and changes in their work organisations, and how they use their knowledge, skills and emotions in coping with stress.

Bounded agency is further characterised by a sense of reflexive self-authorship. Evans (this volume) takes as an example the narrative accounts of middle-aged women who authored certain life events - events which triggered personal and professional development, and which promoted an altered orientation to life trajectories. The life narratives were shown to be empowering for the practice of personal agency in challenging life situations.

Individual employees and their professional identities are considered by Hökkä, Vähäsantanen, Paloniemi and Eteläpelto et al. (this volume) in their chapter which addresses agency from the perspective of emotions. According to the SCSC approach, individual work identity is intertwined with the practice of professional agency, and influences such agency. Reciprocally, the practice of agency influences professional identities, and agency is needed to renegotiate and to craft one's own professional identity.

\subsection{Agency and emotions}

The chapter by Hökkä et al. (this volume) considers the emotions that can be identified in the accounts of employees working in education, and how these emotions are related to the agency 
enacted in their work. From a meta-synthesis of five empirical studies (conducted by the authors), Hökkä et al. identified three major aspects with which emotions were involved; these were (a) professional identity, (b) work, and (c) social relationships. Emotions were categorised as positive and negative. The findings indicated that positive emotions impelled educators to change their professional identities, and thus to practise identity agency. For example, within a curriculum reform, professional agency was enacted through changing and enacting professional identities.

By contrast, negative emotions acted, at least initially, as an obstacle to identity crafting. In experiencing negative emotions, caused by curriculum changes, teachers strengthened their current identity, which was in opposition to the goals of an educational reform. Negative emotions, manifested as disappointment, a sense of unfairness, feelings of inadequacy, and a fear of failure, emerged if employees could not work in accordance with their professional interests, ambitions, and competences. A lack of autonomy, deriving from

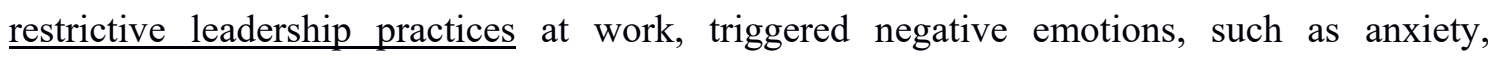
dissatisfaction, frustration, and anger. In some cases these negative emotions caused employees to practise agency by choosing to resign from the current employment, and to find a new workplace within a less restrictive organisation. When this happened, the employees reported highly positive emotions, such as satisfaction, enthusiasm, and enjoyment. Such positive emotions were in general connected to resources which supported the practice of agency by the employees (teachers, educators, and researchers). This meant that they participated, exerted influence, and made choices in their work, and in their work communities. The most important resources for such a practice of agency consisted of supportive relationships with colleagues at work.

Hökkä et al., (this volume) concluded that negative emotions were indeed related to the enactment of professional agency, in terms of both change-oriented and maintenance- 
oriented decisions regarding an employee's professional identity and career. A notable finding among employees was that, initially, fear inhibited the enactment of professional agency, paralysing agentic actions. In contrast, among leaders, fear seemed to have the power to activate the persons concerned. The authors thus concluded that the relationship between emotions and agency at work is connected to issues of power, and to the power relations operating in a given situation.

In a study on leaders' agency and emotions, Hökkä et al. (this volume) further showed that autonomy and independence were major reasons for positive emotions, such as joy and satisfaction. When collegial and social relationships were positive, and when there was collaboration and a sense of making progress, positive feelings, such as joy, confidence, and strength were supported. By contrast, negative emotions - such as frustration, exhaustion, inadequacy, fear, and a sense of oppression - were triggered among leaders by the same restrictions on agency as among employees. The negative feelings emerged from being unable to work in accordance with personal identity commitments, or from having no means to influence upper-level decisions - which for the most part involved demands to raise productivity with decreased resources. Nevertheless, Hökkä et al. demonstrated how leaders moved from the major negative emotion of inadequacy - caused by the high demands they set for themselves - towards greater leniency towards themselves while participating in a one-year leadership coaching program. Within this, they were able to reframe their work identities, in company with other leaders of similar status.

Up to the present there has been insufficient research on how emotions are related to the practice of different kinds of agency at work, especially in connection with work-related learning. In such research, the role of power relations should be carefully considered, since these seem to have a major role as mediators between emotions and agency. 


\section{The connections between agency and learning}

The title of this book refers the ways in which agency and agentic perspectives are related to work-related learning and to development. This indeed points to the original reasons for addressing agency. Most of the authors in this book started to investigate agency at work because they observed agency to be closely intertwined with learning at work. However, as we have seen, differences exist in how work-related learning is understood, and hence also in how it may be connected to agency.

Work-related learning has mostly been understood as practice-based professional development, i.e. as something more than the traditional school-based acquisition of knowledge. Workplace learning is seen as the experience-based development of professional expertise, taking place through social interaction and individual reflection on work practices. In addition, workplace learning takes place through the shared, innovative development of work practices, as well as through employees' competences.

Such an understanding implies that that learning and the practice of agency overlap. This is especially the case regarding the transformative aspect of work agency; within this, agency (understood as the shared development of work practices) overlaps with the notion of learning as something based on behaviour and action. Such notions are prominent in the present book (for example in the chapters by Evans; Goller and Harteis; Hökkä et al.; Hopwood; Messman and Mulder; Smith; Wiethe-Körprich et al.; all in this volume). Viewed in this light, learning and agency come close to being identical, and we arrive at what can be described as an agentic perspective on learning, or put simply, agentic learning. Such agentic learning comprises not only the individual acquisition of new competences, but also transformative changes in work practices. In addition, an agentic perspective implies that learning at work takes place through the crafting and negotiation of work identities (e.g. Hökkä et al., this volume). 
Such learning is also typical among film and TV freelancers (Evans, this volume). These are people who need to invest in "who they are,", which requires constant production of the self at work. Evans understands this as a highly agentic process. It contributes to the individual's own development, while also collectively reproducing and reconstituting TV and film industry norms. Freelancers identify themselves with their craft, with entrepreneurialism, and with capacities to learn. These are integrated practices, combined as a cohesive and coordinated set of actions and activities. The chapter by Evans provides a fascinating description of how this integration occurs.

Other kinds of agentic learning processes are described in an examination of the work of novice nurses (Evans, this volume). For example, a recontextualisation of knowledge takes place when a practitioner recognises a new situation. In this case, the person can experience a feeling of being overwhelmed. This requires a response, impelling the individual towards the acquisition and application of knowledge.

In current working life, agentic activities can also revolve around longer-term processes which, once again, are broadly identical with work-related learning. Such learning can be both individual and collective in nature, taking place through individual and/or shared engagement with developmental activities.

\section{Future avenues of research}

In summarising the previous chapters, we can roughly categorise them according to whether agency is considered in relation to work and production generally, or from the perspective of the individual employee. From the point of view of working life overall, what matters is to provide affordances for enacting agency at work. For the individual employee, on the other hand, agency deserves to be considered from a life-long and life-wide perspective. 
As this book demonstrates, conceptualisations of agency at work have been increasingly linked to professional and work-related learning. The growing interest in the role of agency for work-related learning is manifested in the accounts given here, which include also related concepts, such as innovative work behaviour. All in all, the eight chapters provide comprehensive coverage of the notions applied in theorising agency within work-related learning.

Since the concept of agency has a multidisciplinary background, including in particular the social sciences, it seems appropriate that social science approaches are prominent in most of the notions presented here. In addition, it should be noted that most of authors of this book approach agency from an (adult) education perspective, but that ideas deriving from psychology, philosophy, and organisation research are present also. The concept of agency is by no means limited to any one of these disciplines. Rather, as suggested by Evans, we need to construct multidisciplinary spaces to obtain multifaceted conceptualisations of the phenomenon. Such a multidisciplinary space could position definitions of agency along three major dimensions, emphasising (a) structural vs. individual aspects, (b) transformative vs. reproductive aspects, and (c) external vs. internal aspects. These three dimensions seem to represent the most important coordinates along which understandings of agency can be located. In the future, we may seek analytical lenses in order to "zoom in" to any given aspect on the coordinates.

Moving from theoretical discussion to empirical research, we need empirical modelling of the structure and components of agency. Thus, in addition to qualitative research (which is what has mainly been conducted so far), we will need quantitative instruments to assess agency within different work contexts. So far, there has been a lack of such validated instruments, although there are ongoing attempts to construct them. Such measures could give evidence, for example, on how different kinds of leadership practices are connected to the 
employees' sense of agency. Here it should be noted that, insofar as agency is connected to issues of power, employees' sense of agency at work is strongly linked to varieties and styles of leadership. In addition, forms of social interaction can be expected to influence the emergence of collective agency at work - an aspect which has so far not been studied sufficiently. In these various domains, practical instruments will be needed to measure the levels of agency - including also the lack of it - thus providing the knowledge needed to develop agency in the workplace.

From the perspective of the individual, discussion on agency has recently extended into temporal dimensions, seeking to encompass the past and future as well as the present (Biesta, Priestley and Robinson, 2015). This implies that agency would be linked to not only to individuals' or groups' short-term or situational activities, but also to their long-term life goals, and to the entire life-courses of those concerned. So far, it can be suggested that agency has not been studied sufficiently from a life-course perspective. In addition, longitudinal research strategies and intervention studies are still very much needed. Here, one can point to some recent examples of longitudinal research, addressing in particular how collective agency was developed within a six-month identity coaching intervention (Hökkä et al., 2017; Vähäsantanen et al., 2016). In addition, a study has been conducted in the context of an educational reform. This study indicated how, among teachers, the nature of the agency practised changed over a period of one year, starting from the beginning of the reform (Vähäsantanen, 2015). However, we need more empirical research on how to influence agency, including research on the long-term consequences of interventions aimed at employees' and leaders' learning and development.

Overall, there is a clear need for an individual life-course perspective on the enactment of agency and on the construction of agentic capacities. This is particularly the case within an increasingly complex and unstable global labour market. Within the labour market, 
increasing numbers of people - especially young people - are working as freelancers, casual $\underline{\text { workers, }}$, and zero-hour contract workers. Hence, more research is needed on their practice of agency, and on how to support work-related learning in work that lacks the boundaries provided by traditional work organisations. So far, we have little understanding of the kinds of identity agency enacted in such work, and of the kinds of support required. This is urgent, since policies on developing working life and reducing youth unemployment are highly dependent on the kinds of start-up companies that are emerging outside traditional work organisations, and on the initiatives undertaken by these companies. Growing digitalisation and automation (including the use of robots) will mean less low-skill work, and will change the requirements in more professional work. This implies that people will have to possess new forms of agency for the new jobs that become available.

Within the subject-centred socio-cultural approach to agency, agency is understood as something that is always exercised for certain purposes and within/through certain (historically formed) socio-cultural and material circumstances. It is also constrained and resourced by these circumstances. In researching agency we thus need to specify the kind of agency we are referring to, and the purposes for which it is enacted. To take an example, identity agency involves renegotiating and crafting one's professional identity (Ruohotie-Lyhty and Moate, 2016), whereas epistemic agency refers to solving knowledge-based problems (Hopwood). Agency has indeed been specified in terms of its purpose by Pantic (2015), who refers to agency for social justice.

Another way to specify agency may incorporate the contextual conditions within which professional agency is practised. For example, Pappa, Moate, Ruohtie-Lyhty and Eteläpelto (2017) specify three different forms of agency that apply in teachers' work, referring to classroom-based agency, relational agency, and socio-cultural agency. Hökkä et al. (2017), for their part, have referred to collective agency, which was manifested when a group of arts 
and craft teachers transformed their marginalised professional position within a teacher education organisation (through a group-based identity workshop). In so doing, they achieved a strengthened collective identity, and as a consequence of this, a more empowered position.

Last but not least, for the future we can expect changes in pedagogical methods. These will aim to promote work-related learning through the strengthening of professional agency at work. It can be anticipated that, with the concept of agency as a central focus, there will be new definitions of pedagogical aims, and new practices arising from them.

\section{Acknowledgements}

I would like to warmly thank Donald Adamson for proofreading the manuscript. This work was supported by the Academy of Finland [Grant number 288925, The Role of Emotions in Agentic Learning at Work]

\section{References}

Biesta, G., Priestley, M. \& Robinson, S. (2015). The role of beliefs in teacher agency. Teachers and Teaching: theory and Practice, 21(6), 624-640.

Billett, S. (2008). Learning throughout working life: A relational interdependence between social and individual agency. British Journal of Education Studies, 55 (1), 39-58.

Buchanan. R. (2015). Teacher identity and agency in an era of accountability. Teachers and Teaching: theory and practice, 21(6), 700-719.

Collin, K., Paloniemi, S., \& Vähäsantanen, K. (2015). Multiple forms of professional agency for (non)crafting of work practices in hospital organisation. Nordic Journal of Working Life Studies, 5(3), 63-83. http://rossy.ruc.dk/ojs/index.php/njwls/article/view/4834

Edwards, A. (2005). Relational agency: Learning to be a resourceful practitioner. International Journal of Educational Research, 43(3), 168-182.

Emirbayer, M. \& Mische, A. (1998). What is agency? American Journal of Sociology, 103(4), 962-1023. 
Eteläpelto, A., Vähäsantanen, K., Hökkä, P., \& Paloniemi, S. (2013). What is agency? Conceptualizing professional agency at work. Educational Research Review, 10, 45-65. http://dx.doi.org/10.1016/j.edurev.2013.05.001

Eteläpelto, A., Vähäsantanen, K., Hökkä, P., \& Paloniemi, S. (2014). Identity and agency in professional learning. In S. Billett, C. Harteis \& H. Gruber (Eds.), International Handbook of Research in Professional and Practice-based Learning (pp. 645-672). Dordrecht: Springer.

Eteläpelto, A., Vähäsantanen, K. \& Hökkä. P. (2015). How do novice teachers in Finland perceive their professional agency? Teachers and Teaching: theory and Practice, 21(6), 660680. http://www.tandfonline.com/doi/full/10.1080/13540602.2015.1044327.

Evans, K. (this volume). Bounded agency in professional lives. In M. Goller \& S. Paloniemi (Eds.), Agency at work: An agentic perspective on professional learning and development (pp. $\mathrm{XX}-\mathrm{XX})$.

Goller, M. \& Harteis. C. (this volume). Human agency at work: Towards a clarification and an operationalisation of the concept. In M. Goller \& S. Paloniemi (Eds.), Agency at work: An agentic perspective on professional learning and development (pp. XX-XX).

Harteis, C., \& Goller, M. (2014). New skills for new jobs: Work agency as a necessary condition for successful lifelong learning Promoting, Assessing, Recognizing and Certifying Lifelong Learning (pp. 37-56): Springer.

Hiltin, S. \& Elder, G.H. (2007) Time, self and the curiously abstract concept of agency. Sociological Theory, 25(2), 170-191.

Hopwood, N. (this volume). Agency, learning and knowledge work: epistemic dilemmas in professional practices. In M. Goller \& S. Paloniemi (Eds.), Agency at work: An agentic perspective on professional learning and development (pp. XX-XX).

Hökkä, P., Vähäsantanen, K., \& Mahlakaarto, S. (2017). Teacher educators' collective professional agency and identity: Transforming marginality to strength. Teaching and Teacher Education, 63, 36-46. doi:10.1016/j.tate.2016.12.001

Hökkä, P., Vähäsantanen, K., Paloniemi, S., \& Eteläpelto, A. (this volume). The reciprocal relationship between emotions and agency in the workplace. In M. Goller \& S. Paloniemi 
(Eds.), Agency at work: An agentic perspective on professional learning and development (pp. $\mathrm{XX}-\mathrm{XX})$.

Knorr Cetina, K. (2001). Objectual practice. In T. R. Schatzki, K. Knorr Cetina, \& E. von Savigny (Eds.), The practice turn in contemporary theory (pp. 175-188). London: Routledge.

Kwon, H.W. (this volume). Expanding the notion of agency: Introducing grit as an additional facet of agency. In M. Goller \& S. Paloniemi (Eds.), Agency at work: An agentic perspective on professional learning and development (pp. XX-XX).

Leont'ev, A. N. (1978). Activity, consciousness, and personality. Englewood Cliffs, NJ:

Prentice-Hall Inc.

Messmann, G., \& Mulder, R. H. (this volume). Proactive employees: The relationship between work-related reflection and innovative work behaviour. In M. Goller \& S. Paloniemi (Eds.), Agency at work: An agentic perspective on professional learning and development (pp. XX$\mathrm{XX})$.

Pantic, N. (2015) A model for study of teacher agency for social justice. Teachers and Teaching: theory and practice, 21(6), 759-778.

Pappa, S., Moate, J., Ruohtie-Lyhty, M. \& Eteläpelto, A. (2017). Teacher agency within the Finnish CLIL context: Tensions and resources. International Journal of Bilingual Education and Bilingualism http://dx.doi.org/10.1080/13670050.2017.1286292

Ruohotie-Lyhty, M., \& Moate, J. (2016). Who and how? Preservice teachers as active agents developing professional identities. Teaching and Teacher Education, 55 (April), 318-327. doi:10.1016/j.tate.2016.01.022

Smith, R. (this volume). Three aspects of epistemological agency: The socio-personal construction of work-learning. In M. Goller \& S. Paloniemi (Eds.), Agency at work: An agentic perspective on professional learning and development (pp. XX-XX).

Vähäsantanen, K. (2015). Professional agency in the stream of change: Understanding educational change and teachers' professional identities. Teaching and Teacher Education, 47, 1-12. http://www.sciencedirect.com/science/article/pii/S0742051X14001516 
Vähäsantanen, K., Hökkä, P., Paloniemi, S., Herranen, S., \& Eteläpelto, A. (2016). Professional learning and agency in an identity coaching programme. Professional Development in Education, http://www.tandfonline.com/eprint/FYuMGIBSbIIGezx5mxZP/full

Vähäsantanen, K., Paloniemi, S., Hökkä, P., Eteläpelto, A., \& Räikkönen, E. (2016). Professional agency and learning at work: Developing a practical assessment tool. Paper presented at the EARLI sig 14 Conference. 24.-26.8.2016. Regensburg, Germany.

Wiethe-Körprich, M., Weber, S., Bley, S., \& Kreuzer, C. (this volume). Intrapreneurship competence as a 'manifestation' of work agency - A systematic literature review. In M. Goller \& S. Paloniemi (Eds.), Agency at work: An agentic perspective on professional learning and development (pp. XX-XX).

Vygotskij, L.S., van der Veer, R. \& Valsiner, J. (1994). The Vygotsky reader. Blackwell. 
Figure 1. Subject-centred socio-cultural (SCSC) perspective on professional agency

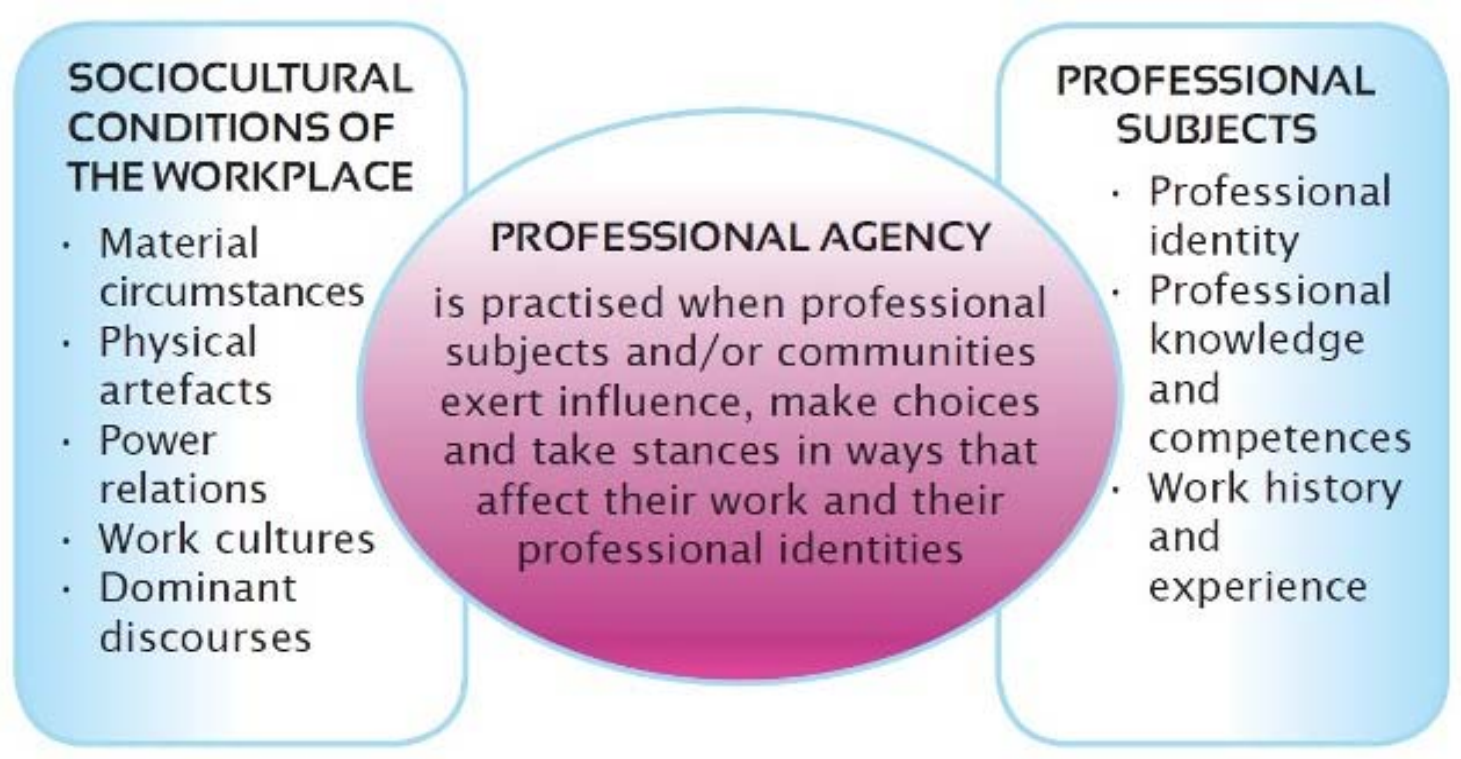

